RESEARCH ARTICLE / ARAŞTIRMA YAZISI

\title{
Yedam Alkol Bağımlılığı Stigmatizasyon Ölçeği
}

\author{
Mehmet DİNÇ ${ }^{1}$, G. Melike ŞİMŞEK ${ }^{2}$, Aylin IŞIK ${ }^{2}$, Kültegin ÖGEL ${ }^{3}$
}

Özet: $\mathrm{Bu}$ çalışmanın amacı, halkın alkol bağımlılığına ilişkin tutumlarını belirlemeye yönelik bir ölçek geliştirmektir. Ölçeğin geliştirilme aşamasında 12 soru oluşturulmuş ve Yeşilay Danışmanlık Merkezi’nde (YEDAM) çalışan 6 uzman görüşüne sunulmuş, 10 olguya pilot olarak uygulanmıştır. Ölçeğin yapı geçerliğini saptamak amacıyla faktör analizi yapılmış ve bu analizler sonucunda3 faktörlü (ahlaki etiketleme, sosyal Ayrımcılık ve kişiliğe yönelik tutum) toplam varyansın \%38.9'unu açıklayan 12 maddeden oluşan ölçek elde edilmiştir. Ölçeğin tümü için Cronbach $\alpha(0.78)$ katsayıları hesaplanmıştır. Elde edilen sonuçlar ölçeğin geçerli ve güvenilir olduğunu kanıtlar niteliktedir.

Anahtar Kelimeler: Bağımlılık, Alkol, Ölçek, Stigma

\section{Yedam Alcohol Dependence Stigmatization Scale}

\begin{abstract}
The aim of this study is to develop a scale which would determine public attitudes towards alcohol addiction. In the process of development of the scale, 12 questions were prepared and presented to 6 specialists working in Yeşilay Counseling Center (YEDAM), applied to 10 cases as pilot applications. In order to detect the structural validity of the scale factor analysis were conducted. As a result of this analys, a 3 factored (moral lebaling, discrimination, attitude towards personality) scale that explains $38.9 \%$ of the total variance and that was comprised of 12 items was obtained. Cronbach's $\alpha(.78)$ coefficients for the totality of the scale were calculated. The obtained results prove that the scale is valid and reliable.
\end{abstract}

Key Words: Addiction, Alcohol, Scale, Stigma

${ }^{1}$ Dr., Hasan Kalyoncu Üniversitesi, Psikoloji Bölümü

${ }^{2}$ Uzm. Psk., Yeşilay Danışmanlık Merkezi (YEDAM)

${ }^{3}$ Prof. Dr., Moodist Psikiyatri ve Nöroloji Hastanesi, İstanbul Bilgi Üniversitesi

Address of correspondence/Yazışma adresi: ${ }^{3}$ Uzm. Psk., Yeşilay Danışmanlık Merkezi (YEDAM) Türkiye-İstanbul. E-mail: aylinisik95@gmail.com

Date of Received/Geliş Tarihi: 25.10.2019, Date of Revision/Düzeltme Tarihi: 02.11.2019, Date of Acceptance/Kabul Tarihi: 06.11.2019

Citing/ Referans Gösterimi: Dinç, M., Şimşek G.M., Işık, A., Ögel, K. (2019). Yedam Alcohol Dependence Stygmatızatıon Scale. Klbrıs Türk Psikiyatri ve Psikoloji Dergisi, 1(Özel Sayı.1): 33-35 doi:10.35365/ctjpp.19.special1.9 


\section{Giriş}

Damgalama birey ve grup hakkındaki klişeleri, ön yargıları ve bireye, gruba yönelik ayrımcılı̆̆ 1 içerir. Bir gruba yönelik düşünceler, duygular ve davranışlardan oluşabilir (2). Alkol bağımlılı̆̆ına ilişkin damgalamalar genellikle ahlaki açıdan düşük değerlilik, kişilik zayıflığ ve suç eğilimi gibi olumsuz tutumlar şeklinde olmaktadır. Damgalama, bağımlı kişilerin sosyal ve psikolojik iyiliği açısından ciddi olumsuz sonuçlar doğuran bir sorun olup, bağımlılığın tedavisinde önemli bir engel teşkil etmektedir (7). Psikolojik ve tıbbi tedavi almayan bireyler zamanla sosyal işlevlerini kaybetme, meslek edinememe, bir işte çalışamama ile karşı karşıya kalır $(4,3)$. Bu durum bağımlılığın sürmesine katkıda bulunan umutsuzluk ve yalnızlık ile sonuçlanmaktadır $(6,5)$. Alkol bağımlıları ile yapılan bir çalışmada gerek hastalar gerekse hasta yakınlarının alkol ve madde bağımlılıklarını benzer şekilde damgaladıkları görülmektedir (1). Bu çalışmanın amacı halkın alkol bağımlısı bireylere yönelik damgalayıcı tutumlarını araştırmaya yönelik geçerli ve güvenilir bir ölçek geliştirmektir.

\section{Yöntem}

\section{Örneklem}

Çalışmanın örneklemi iki ayrı kurumda çalıșan kişilerden seçilmiştir. Kurumlardan birisi özel okul, diğeri ise bir şirkettir. Her iki kurumdan toplam 118 kişi çalışmaya alınmıştır.

\section{Ölçeğin Geliştirilmesi}

Literatür taramasından elde edilen bilgiler ve uzman görüşleri değerlendirilerek bir soru havuzu Tablo 1: Ölçeğin güvenilirlik katsayıları oluşturulmuştur. Soru havuzu oluşturulurken daha önce geliştirilmiş ve bu alanda kullanılan ölçek soruları gözden geçirilmiş, YEDAM Madde Bağımlılığı Stigmatizasyon Ölçeğindeki sorular temel alınarak uyarlama yapılmıştır. Araştırmanın yapıldığı merkezde çalışan 6 uzmana danışılarak, ölçekte kullanılması planlanan 12 soru seçilmiştir. Oluşturulan sorulardan taslak bir ölçek hazırlanmış, pilot olarak 10 olguya uygulanmış, elde edilen bilgiler ve geribildirimler doğrultusunda klinik uygulamada somut veri sağlayacak sorulardan oluşan 12 soruluk bir ölçek geliştirilmiştir. Yanıt seçenekleri, 0-3 puan arasında değerlendirilen dörtlü Likert tipi ölçekten oluşmuştur. Ölçekten alınabilecek puan 0-36 arasındadır. Yanit skalaları “(3) Tamamen katıliyorum”, “(2) katılıyorum", “(1) Katılmıyorum” , “(0) Hiç katılmıyorum" şeklinde düzenlenmiştir. "Alkol bağımlısı olan bir kişiyle birlikte yaşayabilirim", "Alkol bağımlısı olan bir kişiyle birlikte çalışabilirim", "Alkol bağımlılı̆̆ bir hastalıktır", "Alkol bağımlılığı tedavi edilebilir" soruları ters kodlanmıştır.

\section{Uygulama}

Uygulama internet üstünden yapılmıştır. Çalışanların internet üstünden formu doldurması istenmiştir. Her iki kurumda çalışan kişilerin \%80'i formu doldurmayı kabul etmiştir. Formlar anonim olarak doldurulmuştur.

\section{Sonuç}

Ölçekten alınan puanın ortalaması 23.19 \pm 4.71 bulunmuştur. Ölçeğin iç tutarlık analizinde Cronbach Alfa katsayısı 0.78 saptanmıştır (Tablo 1).

\begin{tabular}{|c|c|c|c|c|}
\hline & $\begin{array}{l}\text { Madde } \\
\text { çıktığında } \\
\text { ölçek } \\
\text { ortalaması }\end{array}$ & $\begin{array}{l}\text { Madde } \\
\text { çıtı̆̆ında ölçek } \\
\text { varyansı }\end{array}$ & $\begin{array}{l}\text { Madde-toplam } \\
\text { korelasyonu }\end{array}$ & $\begin{array}{l}\text { Madde } \\
\text { çıktığında } \\
\text { ölçek } \\
\text { Cronbach alfa } \\
\text { katsayısı }\end{array}$ \\
\hline Alkol bağımlıları toplum içinde serbest dolaşmamalıdır & 21,63 & 17,816 &, 556 & ,754 \\
\hline Alkol bağımlısı olan bir kişiyle birlikte yaşayabilirim & 20,07 & 18,138 &, 541 &, 757 \\
\hline Alkol bağımlısı olan bir kişiyle birlikte çalışabilirim & 20,29 & 17,142 & 670 &, 741 \\
\hline Alkol bağımlıları tehlikeli olurlar & 21,39 & 17,706 & ,661 & ,744 \\
\hline Alkol bağımlıları kendi hayatları ile ilgili doğru kararları alamaz & 21,42 & 17,370 & ,738 &, 737 \\
\hline Alkol bağımlılı̆̆g bir ruhsal zayıflık halidir & 21,25 & 18,873 & , 486 &, 764 \\
\hline Alkol bağımlılığı bir hastalıktır & 20,82 & 22,701 &,- 144 &, 831 \\
\hline Alkol bağımlılığı tedavi edilebilir & 21,58 & 22,418 &,- 089 &, 806 \\
\hline Alkol bağımlıları kendilerinden başkasını düşünmezler & 21,81 & 17,850 & ,594 &, 751 \\
\hline Alkol bağımlıları psikopat insanlardır & 22,06 & 19,235 & , 470 &, 766 \\
\hline Alkol bağımlılı̆̆ı bir irade sorunudur & 21,07 & 22,272 &,- 069 &, 810 \\
\hline Alkol bağımlılarının sözüne güvenilmez & 21,70 & 17,222 & ,772 & .737 \\
\hline
\end{tabular}

Verilerin faktör analize uygun olup olmadığını araştırmak için KMO and Barlett's testi uygulanmıştır. KMO değeri 0.80 bulunarak verilerin faktör analizine uygun olduğu tespit edilmiştir $(\mathrm{KMO}>.050 ; \mathrm{p}<0.05)$. Faktör analizi sonucunda ölçeğin maddelerinin, toplam varyansın \%38.9'unu açıklayan 3 faktör altında toplandığ saptanmıştır (Tablo 2). Bunlar sirasıyla ahlaki etkiletleme, sosyal ayrımcılık ve kişiliğe yönelik tutum olarak tanımlanmıştır. 
Tablo 2: YEDAM Alkol Bağımlılı̆̆ı Stigmatizasyon Ölçeğinin Faktör Yapısı

\begin{tabular}{llll}
\hline & Faktör 1 & Faktör 2 & Faktör 3 \\
\hline Alkol bağımlılarının sözüne güvenilmez &, 785 & & \\
Alkol bağımlıları kendilerinden başkasını düşünmezler &, 768 & & \\
Alkol bağımlıları psikopat insanlardır &, 743 & & \\
Alkol bağımlıları toplum içinde serbest dolaşmamalıdır &, 661 & & \\
Alkol bağımlıları tehlikeli olurlar &, 651 &, 849 &, 830 \\
Alkol bağımlıları kendi hayatları ile ilgili doğru kararları alamaz &, 637 & &, 775 \\
Alkol bağımlısı olan bir kişiyle birlikte yaşayabilirim & &, 617 \\
Alkol bağımlısı olan bir kişiyle birlikte çalışabilirim & &,- 606 \\
Alkol bağımlı̆ı̆̆ı bir irade sorunudur & &,- 526 \\
Alkol bağımlı̆ı̆̆ı bir ruhsal zayıflık halidir & & & \\
Alkol bağımlı̆ı̆̆ı bir hastalıktır & & \\
Alkol bağımlı̆ı̆̆ı tedavi edilebilir & & & \\
\hline
\end{tabular}

\section{Tartışma}

Bu bulgular YEDAM Alkol Bağımlılı̆̆ Stigmatizasyon Ölçeği'nin toplum tarafindan alkol bağımlılığını damgalamayı ölçmede güvenilir ve geçerli bir araç olduğunu göstermektedir. Toplumdan dışlanma, evsizlik, işsizlik ve zayıf duygusal baş etme mekanizmaları gibi sorunlarla karşı karşıya olan bağımlının kabul edildiğini ve anlaşıldığını hissetmesi tedaviye erişiminde ilk adımdır. $\mathrm{Bu}$ nedenle, bu çalışma damgalamanın azaltılmasında neler yapılabileceği konusunda tartışmalara katkı sağlayacak niteliktedir. Bu çalışmada toplumun bilgi eksiklerinin giderilmesinde ve damgalamanın söndürülmesinde izlenecek yollar için kullanılabilecek bulguların yer aldığı düşünülmektedir. Türkiye'de damgalamayı azaltmaya yönelik yapılandırılmış eğitim programları, damgalayanlar ile damgalananlar arasında kişisel temas kurmaya odaklı programlar ve damgalanmaya yönelik terapötik görüşme programları gibi çeşitli müdahale uygulamaları geliştirilebileceği ümit edilmektedir.

\section{Kaynaklar}

Arıkan, Z, Genç, Y., Etik, C.., Aslan, S, Parlak, İ. (2004). Stigmatization of the Patients and Their Relatives in Alcohol and Other Substance Dependencies, Journal of Dependence, 5(2).Bahar, A. (2007). Şizofreni ve damgalama. Firat Sağllk Hizmetleri Dergisi, 2(4), 101-110.

Baldwin, M. L., Marcus, S. C., De Simone, J. (2010). Job loss discrimination and former substance use disorders. Drug and alcohol dependence, 110(1-2), 1-7.

Corrigan, P. W., Watson, A. C., Barr, L. (2006). The self-stigma of mental illness: Implications for self-esteem and selfefficacy. Journal of Social and Clinical Psychology, 25(8), 875884.
Gyawali, S., Sarkar, S., Balhara, Y.P.S., Kumar, S., Patil, V., Singh, S. (2018). Perceived stigma and its correlates among treatment seeking alcohol and opioid users at a tertiary care centre in India, Asian Journal of Psychiatry, 37(2), 34-37.

Luoma, J. B., Kohlenberg, B. S., Hayes, S. C., Bunting, K., Rye, A. K. (2009). Reducing self-stigma in substance abuse through acceptance and commitment therapy: Model, manual development, and pilot outcomes. Addiction research and theory, 16(2), 149-165.

Manzo, J.F. (2004) On the sociology and social organization of stigma: some ethno methodological insights. Human Studies, 27, 401-16. 